\title{
Dieting: really harmful, merely ineffective or actually helpful?
}

\author{
Michael R. Lowe* and C. Alix Timko \\ Department of Psychology, Mail Stop 626, Drexel University, 245 N. 15th St, Philadelphia, PA 19102, USA
}

\begin{abstract}
Dieting has developed a negative reputation among many researchers and health care professionals. However, 'dieting' can refer to a variety of behavioural patterns that are associated with different effects on eating and body weight. The wisdom of dieting depends on what kind of dieting is involved, who is doing it, and why. Thus, depending on what one means by the term, dieting can be quite harmful, merely ineffective or actually beneficial. The present paper considers examples of all three. In particular, we argue that judgements about the desirability of dieting should consider the likely consequences to particular individuals of engaging in, or not engaging in, dieting behaviour.
\end{abstract}

\section{Dieting: Behavioural patterns}

Over the past 25 years dieting has developed a negative reputation. This reputation, which is based on several different types of evidence, includes findings showing that:

(1) conscientious objectors who rapidly lost about $25 \%$ of their body weight and were then re-fed developed a variety of emotional and binge-eating problems (Keys et al. 1950);

(2) obese dieters develop a variety of untoward emotional reactions when they lose weight (Stunkard, 1956; Garner \& Wooley, 1991);

(3) most weight lost by dieting is eventually regained (Garner \& Wooley, 1991; Brownell \& Rodin, 1994);

(4) repeatedly losing and regaining weight (weight cycling) has negative physiological and psychological effects (Brownell et al. 1986; Polivy \& Herman, 2002);

(5) dieting in women represents a psychologically unhealthy focus on reshaping the body as a way of conforming with societal norms and expectations for women (Striegel-Moore et al. 1986; Brownell, 1991);

(6) dieting plays a causal role in the aetiology and maintenance of eating disorders (Russell, 1979; Polivy \& Herman, 1985; Wilson et al. 1997);

(7) restrained eating creates a vulnerability to emotional eating and problems with eating regulation (Herman \& Polivy, 1983);

(8) being on a diet creates problems in the efficient processing of information (Jones \& Rogers, 2003).

On the other hand, there are many studies and review papers suggesting that the negative effects of restrained eating and dieting are often illusory or, when they exist, have been exaggerated (Smoller et al. 1987; Lowe 1993, 2004; Brownell \& Rodin, 1994; French \& Jeffrey, 1994; Lowe et al. 1996, 1998). The present paper will not attempt to review all of the 'pros and cons' of dieting behaviour, as several such reviews have already been done (Garner \& Wooley, 1991; Lowe, 1993; Brownell \& Rodin, 1994; French \& Jeffrey, 1994; Foster \& Wadden, 2002). Rather, our purpose is to argue that: (1) it is meaningless to discuss the effects of dieting (or restrained eating) without specifying precisely how the term is being defined; (2) depending on the type of dieting one has in mind, and who is doing it, dieting can be harmful, merely ineffective or beneficial. Examples of each of these alternatives are provided next.

\section{Harmful?}

Perhaps the best-known study of extreme weight loss was conducted by Keys et al. (1950). In the course of the study, a group of normal-weight men was put on a restrictive diet, resulting in a weight loss of $24 \%$ of their starting body weight. After 6 months of food restriction, participants went through a period of re-feeding. The dramatic weight loss had a variety of negative physical and psychological consequences, including preoccupation with food and hunger, depressed mood, irritability, decreased sociability and apathy (Franklin et al. 1948). During the re-feeding phase, the negative effects of semi-starvation were slow to dissipate and were, to some degree, still present after the 12-week phase was over. After the experiment was completed, a small group of men were asked to remain; they were allowed to consume food freely at the weekends. During this period, the remaining participants consumed large amounts of food in one sitting, that is, they engaged in binge eating. Some men continued binge eating even after returning to their original body weight (Franklin et al. 1948; Keys et al. 1950). 
Clinically, the link between extreme weight-loss dieting and binge eating is apparent in the development of bulimia nervosa. Dieting is a risk factor for the development of bulimia nervosa (Stice \& Agras, 1999; National Task Force on the Prevention and Treatment of Obesity, 2000). Many bulimic individuals who present for treatment are in the normal weight range. However, though their normal weight status would usually be viewed as unremarkable, most bulimic individuals' pre-morbid weights are well above their presenting weights. Most bulimic individuals, like all anorexic individuals, lose a large amount of weight in the process of developing their disorder (Garner \& Fairburn, 1988; Russell, 1979). This suppression of weight at an abnormally low level may explain the nutritional deficiencies and hypometabolism found in many individuals with bulimia (MR Lowe, W Davis, D Lucks, R Annunziato and M Butryn, unpublished results). In these results, Lowe et al. predicted that weight suppression (measured as the difference between highest weight ever and current weight) would prospectively predict weight gain during in-patient treatment for bulimia. Controlling for length of hospitalization, weight suppression at admission did in fact predict weight gain during hospitalization (which on average lasted $17 \mathrm{~d}$ ). Controlling for current dieting and previous highest weight (to determine if weight suppression per se was in fact predictive) strengthened this finding. Weight suppression in that study was defined in both absolute and relative terms. Absolute weight suppression referred to the extent to which body weight was below the desirable body weight for a given height, whereas relative weight suppression referred to the extent to which an individual's current body weight was below his or her highest body weight ever. As can be seen in Fig. 1, the two types of weight suppression combined additively to predict weight gain. Those who were highest in absolute weight suppression and in relative weight suppression gained somewhat more weight than the two groups with mixed scores, and gained four times as much weight as those who scored low in both types of weight suppression. Those scoring highest in both types of weight suppression differed significantly from those scoring lowest in both types. Weight gain during hospitalization was also related to clinical improvement on several measures. These results suggest that the existence of a large discrepancy between bulimic individuals'

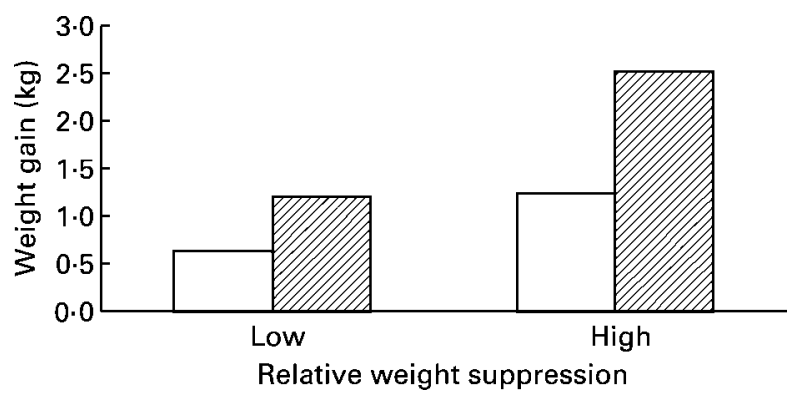

Fig. 1. Relationship of relative and absolute weight suppression to weight gain in bulimic in-patients. $\square$, Low absolute weight suppres-

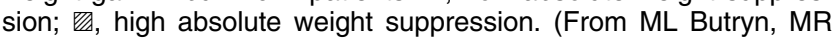
Lowe, DL Safer and WS Agras, unpublished results.) current and highest weights ever may contribute to the maintenance of bulimic symptomatology.

Another recent study found additional evidence that weight suppression could be causally related to the maintenance of bulimia (ML Butryn, MR Lowe, DL Safer and WS Agras, unpublished results). In a reanalysis of data from a multi-site bulimia treatment outcome study (Agras et al. 2002), Lowe et al. found a powerful prospective relationship between level of weight suppression and treatment outcome. Weight suppression was calculated as the difference between patients' highest weight ever and their weight when they entered the study. The level of weight suppression in those who dropped out of the study $(17.73 \mathrm{~kg})$ was much greater than those who completed treatment but were still symptomatic $(8.30 \mathrm{~kg})$, who in turn had greater weight suppression than those who completed treatment and were not symptomatic $(3.76 \mathrm{~kg})$. These findings suggest that weight suppression may be causally related to both the aetiology and maintenance of bulimia and that high levels of weight suppression may interfere with successful treatment.

\section{Merely ineffective?}

In the general population, the type of dieting described earlier involving large, sustained weight loss is relatively rare. Much more common is the more moderate weight losses of overweight dieters. Though many weight-loss programmes are effective in the short term, within several years most or all of the lost weight is regained (Sarwer \& Wadden, 1999). Interestingly, a study by Hensrud et al. (1994) found that this weight regain is not just found among individuals who seek out and participate in formal weight-loss programmes. Hensrud et al. recruited a group of obese women without mentioning weight loss as the goal of the study. These women lost an average of $10 \mathrm{~kg}$ of their starting weight through a controlled diet, but were not taught anything about how to lose weight or maintain a weight loss. These women were then followed for 4 years and their weight regain was compared with the average weight regain of participants who had enrolled in sixteen previous studies of behaviour modification treatment for obesity. The pattern of weight regain in the participants of the study of Hensrud et al. (1994) and in the sixteen comparison studies was quite similar (see Fig. 2), indicating that those who intentionally seek and participate in a weight-control programme reap no weight-control advantage relative to those whose weight loss is neither intentionally sought nor instructionally facilitated.

These results are consistent with the conclusion that in the long-term dieting in overweight individuals is neither beneficial nor harmful, but rather simply ineffective. A similar conclusion has been reached when the psychological effects of diet-induced weight loss in overweight individuals has been studied (Foster \& Wadden, 2002). The beneficial effects of weight loss on self-esteem, body image, binge eating, etc. gradually erode when lost weight is regained. That is, after regaining weight, overweight individuals are neither better off nor worse off psychologically; they essentially return psychologically toward their pre-treatment status. 


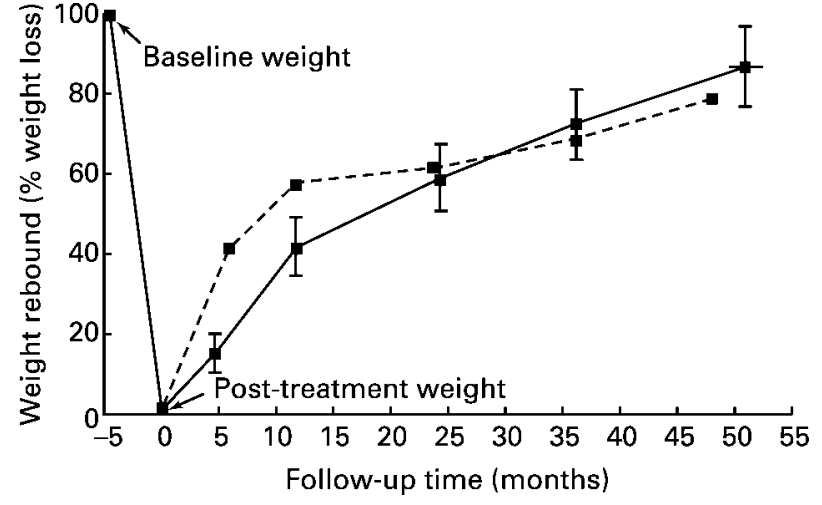

Fig. 2. Weight-rebound pattern of obese females ( $n$ 24) after weight-reduction to normal weight $(-)$ compared with the results in sixteen reports on diet and behaviour modification programmes (--) ( $n$ 58). (From Hensrud et al. 1994; reproduced with permission of the American Journal of Clinical Nutrition ( ${ }^{\circledR}$ American Society for Clinical Nutrition).)

Similarly, there are a number of studies that have found measures of current dieting and restrained eating prospectively predict weight gain over time (Klesges et al. 1989, 1992; French et al. 1994; Stice et al. 1999; Stice, 2001). However, there is little reason to think that dieting causes people to gain weight; rather, dieting may simply be a relatively ineffective means of counteracting biological and environmental influences that promote weight gain (Lowe, 2003). Thus, dieters do not gain weight because they've been dieting, they gain weight despite their dieting.

\section{Actually helpful?}

In considering whether there are types of dieting that may actually be helpful, it is critical to determine why someone is dieting in the first place. If dieting is undertaken to counteract a predisposition that produces overeating or weight gain, then dieting may have mostly beneficial effects. For instance, when obese individuals who engage in binge eating lose weight by dieting, their binge-eating frequency is substantially reduced (National Task Force on the Prevention and Treatment of Obesity, 2000) and remains improved even when weight is regained (Foster et al. 1996).

Normal-weight individuals may also benefit from shortterm diets. Restrained eaters typically eat more after they consume a high-energy preload than after consuming no preload: the so-called counter-regulatory eating effect. However, restrained eaters who say they are currently dieting to lose weight regulate their eating after a preload, just like unrestrained eaters do (Lowe et al. 1991; Lowe, 1995). Furthermore, Presnell \& Stice (2003) found that when normal-weight college students lost a small amount of weight in a weight-loss programme, their level of bulimic symptoms was reduced, not increased.

Similar findings have been reported for bulimic individuals. Lowe et al. (1998) investigated the relationship between the frequency of dieting and the frequency of bingeing in three samples of individuals with bulimia. Infrequent dieters were defined as those who dieted to lose weight rarely or not at all in the recent past; frequent dieters were often or always on diets to lose weight. Lowe et al. (1998) found that frequent dieters binged (and purged) significantly less often than infrequent dieters. In short, in these samples of bulimic individuals, dieting more often to lose weight appeared to protect against bingeing. Of course, bulimic individuals are best served by not engaging in dieting behaviour at all, but among those who are actively bulimic, self-imposed dietary restriction may reduce binge eating (and subsequent purging) relative to bulimic individuals who do not consciously restrict their intake.

\section{Implications}

The purpose of the present brief review is to illustrate several points. First, the merits of 'dieting' cannot be determined without first specifying exactly what one means by the term (Lowe, 1993; French \& Jeffrey, 1994). Second, the potential advantages and disadvantages of dieting will depend on who is dieting and why they are dieting (e.g. to lose weight or to avoid weight gain). In particular, the debate over dieting has largely ignored the significance of a person's propensity toward weight gain. Dieting to lose weight is far more appropriate for an overweight, middle-aged man with risk factors for heart disease than it is for a normal-weight female teenager who is not susceptible to weight gain, but nonetheless feels like she is too fat. We should put behind us general conclusions about the appropriateness of the catch-all term 'dieting' and base such judgements on a thorough specification of the contextual factors upon which such evaluations should be based.

\section{References}

Agras WS, Crow SJ, Halmi KA, Mitchell JE, Wilson GT \& Kraemer HC (2002) Outcome predictors for the cognitive behavior treatment of bulimia nervosa: Data from a multisite study. Am J Psychiatr 157, 1302-1308.

Brownell KD (1991) Dieting and the search for the perfect body: where physiology and culture collide. Behav Ther 22, 1-12.

Brownell KD, Greenwood MR, Stellar E \& Shrager EE (1986) The effects of repeated cycles of weight loss and regain in rats. Physiol Behav 38, 459-464.

Brownell KD \& Rodin J (1994) The dieting maelstrom: is it possible and advisable to lose weight? Am Psychol 49, $781-791$.

Foster GD \& Wadden TA (2002) Social and psychological effects of weight loss. In Eating Disorders and Obesity, 2nd ed., pp. 500-504 [CG Fairburn and KD Brownell, editors]. London: The Guilford Press.

Foster GD, Wadden TA, Kendall PC, Stunkard AJ \& Vogt RA (1996) Psychological effects of weight loss and regain: a prospective evaluation. J Consult Clin Psychol 64, 752-757.

Franklin JC, Schiele BC, Brozek J \& Keys A (1948) Observations on human behavior in experimental semistarvation and rehabilitation. J Clin Psychol 4, 28-45.

French SA \& Jeffery RW (1994) Consequences of dieting to lose weight: effects on physical and mental health. Health Psychol 13, 195-212.

French SA, Jeffrey RW \& Wing RR (1994) Food intake and physical activity: a comparison of three measures dieting. Addict Behav 19, 401-409.

Garner DM \& Fairburn CG (1988) Relationship between anorexia 
nervosa and bulimia nervosa: diagnostic implications. In Diagnostic Issues in Anorexia Nervosa and Bulimia Nervosa, pp. 56-79 [DM Garner and PE Garfinkel, editors]. Philadelphia, PA: Brunner/Mazel, Inc.

Garner DM \& Wooley S (1991) Confronting the failure of behavioral and dietary treatments for obesity. Clin Psychol Rev 11, 729-780.

Hensrud DD, Weinsier RL, Darnell BE \& Hunter GR (1994) A prospective study of weight maintenance in obese subjects reduced to normal weight without weight-loss training. Am J Clin Nutr 60, 688-694.

Herman CP \& Polivy J (1983) A boundary model for the regulation of eating. Psychiatr Ann 13, 918-927.

Jones N \& Rogers PJ (2003) Preoccupation, food, and failure: an investigation of cognitive performance deficits in dieters. Int $J$ Eat Disord 33, 185-192.

Keys A, Brozek J, Henschel A, Mickelsen O \& Taylor HL (1950) The Biology of Human Starvation. Oxford, MN: University of Minnesota Press.

Klesges RC, Isbell TR \& Klesges LM (1992) Relationship between dietary restraint, energy intake, physical activity, and body weight: a prospective analysis. J Abnorm Psychol 101, 668-674.

Klesges RC, Klem ML \& Bene CR (1989) Effects of dietary restraint, obesity, and gender on holiday eating behavior and weight gain. J Abnorm Psychol 98, 499-503.

Lowe MR (1993) The effects of dieting on eating behavior: a three-factor model. Psychol Bull 114, 100-121.

Lowe MR (1995) Restrained eating and dieting: replication of their divergent effects on eating regulation. Appetite 25, $115-118$.

Lowe MR (2003) Self-regulation in the prevention and treatment of obesity: is it feasible? Obes Res 11, Suppl. 1, 445-595.

Lowe MR, Gleaves DH, DiSimone-Weiss RT, Furgueson C, Gayda CA, Kolsky PA, Neal-Walden T, Nelsen LA \& McKinney S (1996) Restraint, dieting, and the continuum model of bulimia nervosa. J Abnorm Psychol 105, 508-517.

Lowe MR, Gleaves DH \& Murphy-Eberenz KP (1998) On the relation of dieting and binging in bulimia nervosa. J Abnorm Psychol 107, 263-271.

Lowe MR, Whitlow JW \& Bellwoar V (1991) Eating regulation:
The role of restraint, dieting, and weight. Int J Eat Disord 10, 461-471.

National Task Force on the Prevention and Treatment of Obesity (2000) Dieting and the development of eating disorders in overweight and obese adults. Arch Intern Med 160, 2581-2589.

Polivy J \& Herman CP (1985) Dieting and binging: a causal analysis. Am Psychol 40, 193-201.

Polivy J \& Herman CP (2002) Experimental studies of dieting. In Eating Disorders and Obesity: A Comprehensive Handbook, 2nd ed., pp. 84-87 [CG Fairburn and KD Brownell, editors]. New York: Guilford Press.

Presnell K \& Stice E (2003) An experimental test of the effect of weight-loss dieting on bulimic pathology: Tipping the scales in a different direction. J Abnorm Psychol 112, 166-170.

Russell G (1979) Bulimia nervosa: An ominous variant of anorexia nervosa. Psychol Med 9, 429-448.

Sarwer DB \& Wadden TA (1999) The treatment of obesity: what's new, what's recommended. J Womens Health Gend Based Med 8, 483-493.

Smoller JW, Wadden TA \& Stunkard AJ (1987) Dieting and depression: a critical review. J Psychosom Res 31, 429-440.

Stice E (2001) A prospective test of the dual pathway model of bulimic pathology: mediating effects of dieting and negative affect. J Psychosom Res 110, 124-135.

Stice E \& Agras WS (1999) Subtyping bulimic women along dietary restraint and negative affect dimensions. J Consult Clin Psychol 67, 460-469.

Stice E, Cameron R, Killen JD, Hayward C \& Taylor CB (1999) Naturalistic weight reduction efforts prospectively predict growth in relative weight and onset of obesity in adolescent females. J Consult Clin Psychol 67, 967-974.

Striegel-Moore RH, Silberstein LR \& Rodin J (1986) Toward an understanding of risk factors for bulimia. Am Psychol 41, $246-263$.

Stunkard AJ (1956) The "dieting depression": untoward responses to weight reduction regimens among certain obese women. $J$ Nerv Ment Dis 123, 194.

Wilson GT, Fairburn CG \& Agras WS (1997) Cognitive-behavioral therapy for bulimia nervosa. In Handbook of Treatment for Eating Disorders, pp. 67-93 [DM Garner and PE Garfinkel, editors]. New York: Guilford Press. 